\title{
MEMES E GIFS COMO FERRAMENTAS DE APRENDIZAGEM CRÍTICA DA LEITURA E DA ESCRITA
}

\section{MEMES AND GIFS AS CRITICAL LEARNING TOOLS OF READING AND WRITING}

\section{CONDE, ÉRICA PIRES}

PROFESSORA ADJUNTA - NÍVEL III DA UNIVERSIDADE FEDERAL DO PIAUÍ, LOTADA NO CENTRO DE CIÊNCIAS DA EDUCAÇÃO - CCE, NO DEPARTAMENTO DE MÉTODOS E TÉCNICAS DE ENSINODMTE, COM MESTRADO EM LINGUÍSTICA PELA UFC (UNIVERSIDADE FEDERAL DO CEARÁ) E EM EDUCAÇÃO, ADMINISTRAÇÃO E COMUNICAÇÃO PELA UNIVERSIDADE SÃO MARCOS - SÃO PAULO.

E-MAIL: ERICA.UFPI@GMAIL.COM

ORCID ID: HTTPS://ORCID.ORG/0000-0003-0473-7870

\section{SOARES, MARIA VILANI}

DOUTORA E MESTRE EM LINGUÍSTICA (UFC), ESPECIALISTA EM LÍNGUA PORTUGUESA (UFPI), GRADUADA EM LETRAS (UFPI). ATUALMENTE É PROFESSORA ASSOCIADA DO CAMPUS MINISTRO PETRÔNIO PORTELA - UFPI- TERESINA, LOTADA NO DEPARTAMENTO DE MÉTODOS E TÉCNICAS DE ENSINO (DMTE/CCE). DOCENTE ORIENTADORA DO PROGRAMA DE RESIDÊNCIA PEDAGÓGICA LETRAS (PRP/CAPES/UFPI), TRABALHANDO MAIS ESPECIFICAMENTE COM PESQUISAS EM ESTÁGIO SUPERVISIONADO E FORMAÇÃO DE PROFESSORES.

E-MAIL: VILANILTON@BOL.COM.BR

ORCID ID: HTTPS://ORCID.ORG/0000-0002-5782-2449

\section{RESUMO}

A realidade vivida no ciberespaço nem sempre invade a sala de aula, passando a impressão de que o ambiente real e o virtual não são usados concomitantemente por professores e alunos. Partindo desse pressuposto, indagamos: De que maneira os Memes e os GIFS contribuem para o ensino e aprendizagem da leitura e da escrita em língua portuguesa? Foram nossos objetivos específicos: analisar memes e GIFS; defender a presença desses gêneros digitais na aula de língua portuguesa e destacar a importância de ações pedagógicas com a leitura e produção de texto, mediante o uso desses textos. A pesquisa realizada tem caráter qualitativo. Embasamos nosso estudo em autores como Marcuschi (2008), Fiorin (2008), Bazerman (2011), Rojo e Barbosa (2015), Lupinacci (2016), Escalante (2016), Massaruto, Vale e Alaimo (2017), além de outros. O resultado mostra a importância de o professor de língua portuguesa fazer uso de Memes e de GIFS, em sala de aula, 
uma vez que viabilizam a criação de leitores e produtores de textos críticos.

PALAVRAS-CHAVE: Gêneros Digitais. Memes e GIF. Aula de Português.

\section{ABSTRACT}

The reality in cyberspace doesn't always invades the classroom, passing under the impression that the real and the virtual environment are not used at the same time by teachers and students. Starting from this assumption, we inquired: how the Memes and the GIFS contribute to the teaching and learning of reading and writing in Portuguese language? Were our specific objectives: analyze memes and GIFS; defend the presence of these digital genres in Portuguese language class and highlight the importance of pedagogical actions with reading and text production, through the use of these texts. The survey has a qualitative character. Embasamos our study in authors like Depends (2008), Fiorin (2008), Bazerman (2011), Rojo and Barbosa (2015), Lupinacci (2016), Escalante (2016), Massaruto, Vale and Alaimo (2017), among others. The result shows the importance of the Portuguese language teacher make use of Memes and GIFS, in the classroom, once you enable the creation of readers and overall.

KEY-WORDS: Refundamentar Digitais. Memes e GIF. Aula de Português.

\section{INTRODUÇÃO}

Vivemos em uma sociedade que diariamente faz uso de tecnologias. Esse fato é tão notório que seria até impossível perceber o mundo sem as conquistas tecnológicas. Diante desses avanços, presenciamos o surgimento de gêneros digitais que acompanham os movimentos sociais. Dentre eles, encontramos os memes e os GIFS, usados especificamente em espaços virtuais e que surgem para ampliar as comunicações travadas nesse ambiente.

No entanto, nem sempre, a realidade vivida no ciberespaço invade a sala de aula, porque ela, por si só, não é capaz de mudar a prática docente. Não há dúvida alguma de que a produção de textos e a leitura que se realizam nas redes sociais parecem ser ainda distantes do contexto escolar. Isso passa a impressão de que os dois ambientes, o real e o virtual, não são vividos concomitantemente. 
Assim, indagamos: De que maneira os Memes e os GIFS contribuem para o ensino e aprendizagem da leitura e da escrita em língua portuguesa? Nosso objetivo geral é mostrar a contribuição dos Memes e GIFS para o aprendizado da leitura e da escrita em aulas de língua portuguesa. Foram nossos objetivos específicos: analisar memes e GIFS; defender a presença desses gêneros digitais na aula de língua portuguesa e destacar a importância de ações pedagógicas com a leitura e produção de texto, mediante o uso de memes e GIFS em aulas de língua portuguesa.

A pesquisa realizada tem caráter qualitativo, uma vez que analisa memes e GIFS e aponta a possibilidade de usos desses gêneros nas aulas de língua portuguesa. Embasamos nosso estudo em autores como Marcuschi (2008), Fiorin (2008), Bazerman (2011), Rojo e Barbosa (2015) e outros, os quais discutem sobre os gêneros digitais; e Lupinacci (2016), Escalante (2016), Massaruto, Vale e Alaimo (2017), além de outros, que estudam os GIFS e memes.

Com os Memes e os GIFS podemos conquistar um aprendizado de língua mais crítico e simultaneamente lúdico, porque para ler e produzir esses gêneros é preciso trabalhar com a polifonia, além de termos uma ação pedagógica que se sustentará em locus digital.

\section{GÊNEROS TEXTUAIS DIGITAIS}

Entender os gêneros textuais é começar por fazer uma diferença entre domínios discursivos, gêneros textuais, tipos textuais e suporte. Marcuschi (2005) mostra os domínios discursivos como algo bastante abrangente, porque não se limita a um único gênero, sendo, portanto, uma esfera de atividade humana. Os gêneros, por sua vez, apresentamse em rotinas sociais, uma vez que não é possível a comunicação sem a produção deles: "[...] é impossível não se comunicar verbalmente por algum gênero, assim como é impossível não se comunicar verbalmente por algum texto. Isso porque toda a manifestação verbal se dá sempre por meio de textos realizados em algum gênero". (MARCUSCHI, 2008, p. 154)

Dessa maneira, para que a comunicação aconteça, precisamos ser produtores de gêneros em situações diferentes. Nas contribuições de Bazerman (2011) sobre gêneros textuais, também encontramos a importância social dada ao assunto, ou seja, não havemos de falar apenas em formas textuais, mas na maneira de organizarmos nossas atividades comunicativas. 
Na mesma esteira de ideias, Rojo e Barbosa (2015, p.17) defendem que todas as nossas práticas sociais com a leitura e com a escrita se concretizam por meio de gêneros. Os gêneros "permeiam nossa vida diária e organizam nossa comunicação"

É preciso também entender que os tipos textuais são elementos constitutivos dos gêneros. Na visão de Marcuschi (2008), tipo textual corresponde à parte que predomina as sequências linguísticas. Por fim, a definição de suporte torna-se também essencial nesse estudo, uma vez que se apresenta como "locus físico ou virtual", "base ou ambiente de fixação do gênero" (MARCUSCHI, 2008, p. 174).

Fiorin (2008, p. 65) faz uma relação diretamente proporcional entre esferas de atividades sociais e os gêneros produzidos. O autor descreve que os gêneros estão em constante alteração, podendo aparecer, desaparecer, diferenciar-se e até ganhar um novo sentido.

Sobre o locus virtual, o autor enfatiza que gêneros novos se proliferam com o surgimento das novas tecnologias e que é preciso pesquisar esses textos. Para ele, a importância dada a esses novos gêneros tem quatro aspectos: estão em desenvolvimento e fase de fixação por meio do uso que se faz deles; apresentam características próprias apesar de alguns parecerem projeções ou transmutações de outros (Cf. MARCUSCHI, 2008, p.202); temos, por meio deles, a possibilidade de rever as questões de textualidade e, por fim, mudam a relação que temos com a oralidade e a escrita.

Rojo (2013) diz que os gêneros digitais são textos produzidos e que circulam no ambiente virtual. Ela destaca que esses gêneros apresentam novos modos de leitura, uma vez que privilegia a relação entre o texto escrito e o texto imagético. Mesmo incentivando pesquisas no contexto virtual sobre gêneros, observa Marcuschi (2010a) que é necessário ter cautela no momento da caracterização dos gêneros digitais.

\section{OS GÊNEROS DIGITAIS NO CONTEXTO ESCOLAR}

Scheneuwly e Dolz (2004, p.74), destacam que os gêneros textuais são a base para se trabalhar o ensino da língua portuguesa "é através dos gêneros que as práticas de linguagem materializam-se nas atividades dos aprendizes". Para os autores, a escola torna-se responsável por inserir em seus currículos práticas sociais autênticas de produção e recepção de textos.

É notório que hoje a sociedade da informação traz exigências como ler e escrever no meio digital. Quando aprendemos a fazer uso 
desses textos, passamos a ter acesso a diferentes práticas sociais. Soares (2002) alerta para a necessidade do trabalho com o letramento digital. Para ela,

A tela, como novo espaço de escrita, traz significativas mudanças nas formas de interação entre escritor e leitor, entre escritor e texto, entre leitor e texto e, até mesmo, mais amplamente, entre o ser humano e o conhecimento. (...) A hipótese é de que essas mudanças tenham consequências sociais, cognitivas e discursivas, e estejam, assim, configurando um letramento digital, isto é, um certo estado ou condição que adquirem os que se apropriam da nova tecnologia digital e exercem práticas de leitura e de escrita na tela, diferente do estado ou condição - do letramento dos que exercem práticas de leitura e de escrita no papel. (SOARES, 2002, p. 146)

Essa nova prática social chega à escola, porque os alunos são assíduos usuários de tecnologias. Nesse sentido, ao abrir as portas da sala de aula para o letramento digital, criamos a possibilidade de desenvolver práticas pedagógicas mais dinâmicas e reflexivas. Xavier (2005) expõe a possibilidade de o professor de língua portuguesa tornar sua aula mais dinâmica, mais empolgante e atraente:

Os professores de língua portuguesa poderiam utilizar estes gêneros digitais para dinamizar suas aulas de produção textual. A mudança de ambiente, da sala de aula para o laboratório de informática, e a descoberta das características e potencialidades de desenvolvimento retórico-argumentativo poderiam tornar a aula de português mais empolgantes e atraente. A participação constante dos alunos em tende a ampliar sua capacidade de argumentar sobre temas diversos, levando-os a aprender a refletir dialeticamente sobre as diversas opiniões e construir sua própria síntese sobre as questões em discussão. (...) Desta forma, os gêneros digitais são megaferramentas para desenvolver nos aprendizes a necessária habilidade de construir pontos de vista e defendê-los convincentemente. (XAVIER; 2005, p.37-38) 
Assim, conforme o texto supracitado, os professores de língua portuguesa precisam usar os gêneros digitais para atualizar suas aulas de produção textual. Podemos, então, destacar que as novas tecnologias possibilitaram maiores trocas interativas e, consequentemente, surgiram gêneros para retratar esse tipo de comunicação. Nesse contexto, aparece o professor de língua portuguesa que precisa conhecer e fazer usos desses gêneros para poder ensinar.

Os gêneros digitais, no ciberespaço, passam a ser grandes ferramentas educacionais para o processo de ensino e aprendizagem. O uso deles, em sala de aula, cria uma importante ação para o desenvolvimento e aumento da competência discursiva dos alunos nos contextos digitais. Xavier (2005) enfatiza que o gênero digital favorece o desenvolvimento acadêmico-intelectual das crianças e adolescentes, pois faz com que os alunos escrevam seus posicionamentos.

Lais (sd), na mesma esteira, mostra a possibilidade de os professores de língua portuguesa trabalharem com os gêneros digitais os diferentes modos de escrita da língua, enfatizando que a mudança se dá mediante a troca de gênero e de suporte. Para a autora, proporcionar produção de gêneros digitais em sala de aula é aproveitar a competência comunicativa que os jovens usam nas redes sociais, com o intuito de transformá-los em bons produtores de texto.

As tecnologias, quando adentram no contexto escolar, trazem benefícios para o ensino e aprendizagem. Para aprendizagem, porque facilita a pesquisa para alunos e para professores e desperta o interesse dos discentes pela produção de textos. Para o ensino, pois cria a possibilidade de o professor usar novos métodos, além de efetivar o seu papel de facilitador da aprendizagem.

Ramos (2012) expõe que os discentes necessitam de orientações e acompanhamento dos docentes no que se refere à busca de informação nos contextos diversos, ou seja, além de pesquisar, há a necessidade de saber escolher, refletir e posicionar- se ante a tantos conteúdos a que somos expostos. Por isso, a autora mostra que, nas instituições educacionais, os professores precisam conhecer e usar as novas tecnologias como conteúdo de ensino e aprendizagem.

Belloni (2001) alerta que, com as novas tecnologias, podemos ser até os mesmos professores, mas nossos alunos são outros. Essa mudança, para ela, gerou insegurança nos docentes, pois sabem que estão despreparados e não conseguiram acompanhar os avanços tecnológicos que adentraram na escola do século XXI. 
Assim sendo, ficou evidente que a aprendizagem passou a ter uma nova roupagem, requerendo do professor um posicionamento de uso das tecnologias de produção, diante da transmissão de informações. Nos PCN, encontramos a relação direta entre o domínio da língua e a participação social, destacando o papel da escola:

O domínio da língua tem estreita relação com a possibilidade de plena participação social, pois é por meio dela que o homem se comunica, tem acesso à informação, expressa e defende pontos de vista, partilha ou constrói visões de mundo, produz conhecimento. Assim, um projeto educativo comprometido com a democratização social e cultural atribui à escola a função e a responsabilidade de garantir a todos os seus alunos o acesso aos saberes linguísticos necessários para o exercício da cidadania, direito inalienável de todos. (BRASIL,1998, p. 21)

A função do professor de língua portuguesa, portanto, seria delineada como um criador de espaços, possibilitando a articulação entre tecnologia-gênero-aluno, estreitando a relação entre linguagem e participação social. Vale destacar que é necessário deixar espaço para que discussões e práticas sobre linguagens e contexto tornem o ensino da língua portuguesa mais prazeroso

\section{MEMES E GIFS EM SALA DE AULA: UMA FORMA DE LER E ESCREVER PAUTADA NA REALIDADE.}

A popularização das tecnologias de informação e de comunicação leva-nos a ter contatos com gêneros digitais diversos. Nesses termos, segundo Marcuschi (2010), presenciamos uma explosão de novos gêneros e novas formas de comunicação, tanto na oralidade como na escrita. Esses gêneros mesclam características dos gêneros impressos com atributos próprios, uma vez que circulam no meio digital.

Como o espaço cibernético está muito usado por crianças e jovens, defendemos a importância de a escola tratar as práticas de leitura e escrita do meio digital. Para tanto, escolhemos os GIFS e os memes, porque houve o uso excessivo desses dois gêneros nas redes sociais, especialmente no WhatSapp.

Para Lupinacci (2016), Arquivos GIF podem consistir de imagens estáticas como também de imagens animadas, com uma resolução baixa, 
que permite uma visualização digital. Além de ter uma duração de dois e cinco segundos. O autor diz que os GIFS não podem ser nem fotografia, nem cinema, mas um intermediário, ou seja, imagens presas em um loop de slguns segundos. Hoje esses gêneros estão com uma nova roupagem, porque usam animações.

Analisamos 20 GIFS e constatamos que as imagens, regra geral, faziam referencias a fatos do cotidiano das pessoas (no caso, preferimos enfatizar fatos políticos) ou a expressões do corpo, sentimentos e emoções. O quadro abaixo traz três exemplos de GIFS que fizeram parte de nossa análise.

Quadro1: Exemplos de GIFS
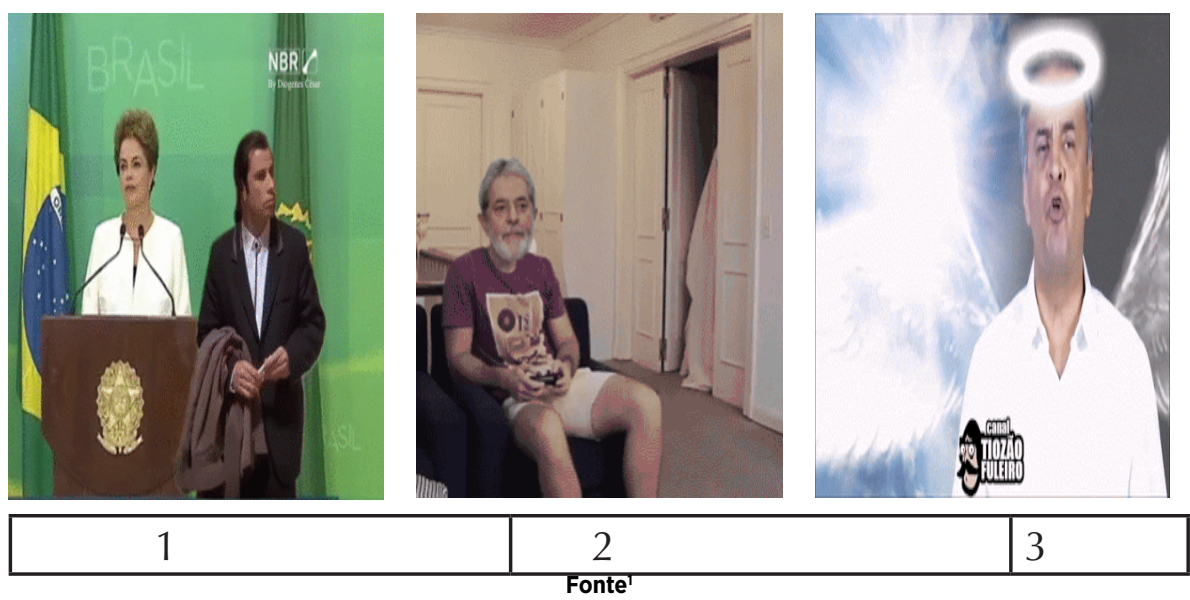

Os GIFS colocados como exemplos apresentaram o contexto político do Brasil, respectivamente, crítica ao governo Temer, a prisão de Lula e A inocência de um político ao falar sobre desvios de verbas públicas. Enfatizar esses gêneros, em aulas de língua portuguesa, é poder tecer críticas à realidade.

11. Fonte: https://www.humorpolitico.com.br/tag/gif-humor/

Gif - Cadê a moçada com a camisa da CBF para apoiar o governo Temer? A gif em questão enfatiza o movimento dos dois a procura de pessoas.Crítica a baixa popularidade do governo Temer no Brasil, após a saída da Dilma como presidenta.Publicado em 24.05. 2016

2. Fonte: https://www.humorpolitico.com.br/tag/gif-humor/

GIF - Lula sendo preso por japonês da federal. Mostra que a polícia federal vai prender Lula de surpresa. Publicado em Publicado em 04/03/2016

3. Fonte: http://temperoseapimentadas.com.br/portal/o-stf-esta-tao-desacreditado-que-os-politicos-ignoram-assuas-decisoes/

GIF com crítica direcionada a Aécio Neves que não foi afastado do senado. Aécio dando uma de anjo. 
O outro gênero digital analisado foram os memes, que para Fontanella (2009) tem baixa qualidade técnica, são realizados de forma lúdica, provocando efeito risível. Ela enfatiza que o termo Meme é usado nas práticas sociais para indicar ideias, brincadeiras, jogos ou até comportamentos, apresentando-se de forma repetida, manifestando-se por meio de vídeos, frases, hashtags, fotolegendas, tirinhas, entre outros.

Segundo a autora, usar memes é ter a possibilidade de trabalhar com o estudo e a leitura de textos escritos e imagéticos, ou seja, textos sincréticos. Isso é interessante no contesto da sala de aula, porque possibilita o aluno interpretar o mundo que o rodeia. Com os memes há a possibilidade de ensinar o alunado a ler imagens, criar textos com base nelas e, pensamos, o mais importante, ser capaz de criticar.

O memeé um gênero que utiliza muito o humor. Para Massaruto, Vale e Alaimo ( 2017, p.2):

Memes, como uma criação relativamente nova e engraçada, podem ser utilizados no cotidiano da sala de aula como uma forma de produção do conhecimento e análise crítica da nossa sociedade. Trabalhados também como gênero textual e aproximados dos gêneros como charge e cartum que, como o meme, utilizam-se do humor para comunicar uma mensagem de forma rápida, que pode ser ou não uma crítica ao estado atual da sociedade.

É perceptível, na citação acima, o caráter de humor encontrado nos Memes. Isso é um ponto relevante para atrairmos os alunos do ensino fundamental e médio para a produção e leitura desses textos. Escalante (2016) mostra que criar/compartilhar memes e GIFS é uma nova habilidade de "ler e escrever", no entanto, para entender esse texto, é preciso que o aluno faça uso da intertextualidade, ou seja, seja capaz de ver um texto em outro. Conforme Regis, Audi e Maia (2014, p. 11): "além dos saberes teóricos, inteligência prática, capacidade de conexão/ associação, criatividade e outras habilidades e recursos".

Então, no momento em que o professor se habilita a trabalhar com os memes e GIFS, em sala de aula, vai propor a seus alunos uma conexão com outros textos e saberes presentes na sociedade. Para essa pesquisa, analisamos 20 memes, dos quais escolhemos três. 


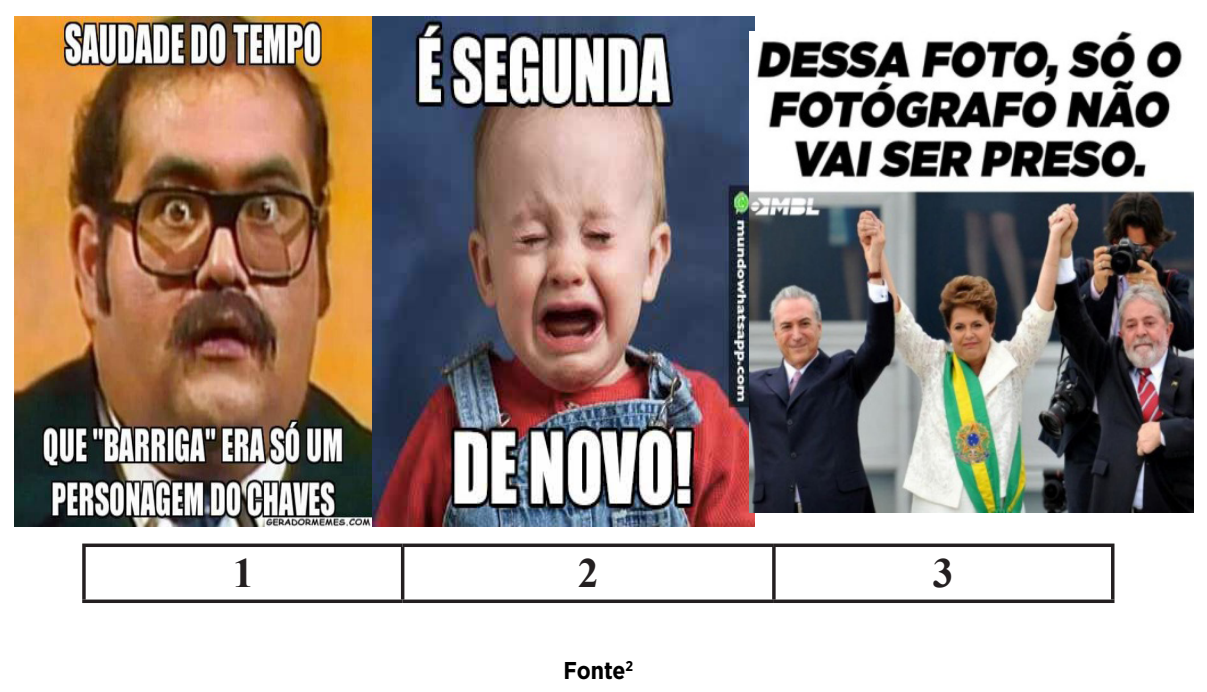

Observamos que, no exemplo 1, temos a intertextualidade com o programa Chaves. Para trabalharmos a interpretação do texto será preciso fazer inferências com do Meme com outro texto; além de perceber que a ambiguidade se destaca no texto verbal com a palavra barriga. O exemplo 2 traz um bebê que chora por ser novamente segunda-feira. Nesse texto, teremos que fazer a inter-relação com o que se usa no cotidiano quanto ao segundo dia da semana. Por fim, o exemplo 3, que apresenta um fato da política do Brasil, a operação conhecida por Lava-jato, que descobriu crime cometido por vários políticos brasileiros. Percebemos que em todos os memes há a o uso da linguagem multimodal, os fatos estão presentes no cotidiano das pessoas, e há uma forma lúdica de produção de texto.

Após a análise dos memes e GIFS acima, podemos observar alguns pontos que merecem ser destacados sobre a importância da leitura e da produção de memes e GIFS na sala de aula. Para isso, construímos um quadro (3), destacando as habilidades desenvolvidas com a leitura e escritura desses gêneros digitais.

\footnotetext{
21 . //www.eonline.com/br/news/601987/os-memes-mais-engracados-do-chaves-e-sua-turma

2. //muitobacana.com/memes-engracados-para-whatsapp/

3. //http://bugg.com.br/2017/05/18/memes-para-amenizar-a-crise-politica/
} 
Quadro 3: O porquê de ler e produzir memes e GIFS em aulas de português.

\begin{tabular}{|l|l|}
\hline \multicolumn{1}{|c|}{ LER } & \multicolumn{1}{c|}{ PRODUZIR } \\
\hline Identificar a intertextualidade & $\begin{array}{l}\text { Trabalhar de maneira lúdica, bus- } \\
\text { cando fazer menção aos textos } \\
\text { que circulam na sociedade; }\end{array}$ \\
\hline $\begin{array}{l}\text { Entender as ambiguidades e o uso } \\
\text { das figuras de linguagem }\end{array}$ & Usar ambiguidade e ironia \\
\hline Ler textos verbais e não verbais; & $\begin{array}{l}\text { Exercitar o uso da linguagem } \\
\text { multimodal; }\end{array}$ \\
\hline $\begin{array}{l}\text { Aprender a entender a realidade, } \\
\text { tornando-se um leitor crítico. }\end{array}$ & $\begin{array}{l}\text { Fazer uso da realidade na cons- } \\
\text { trução de textos. }\end{array}$ \\
\hline
\end{tabular}

Apontamos, assim, os ganhos que os professores de língua portuguesa terão, no contexto da sala de aula, com o trabalho com GIFS e memes. Na leitura, poderemos usar da intertextualidade, ambiguidade e figuras de linguagem; na escrita, poderemos exercitar o uso da ambiguidade e da ironia, da linguagem multimodal e, principalmente, construir textos de maneira lúdica.

\section{CONSIDERAÇÕES FINAIS}

A escola precisa saber lidar com os gêneros virtuais, porque os alunos são assíduos usuários do ciberespaço. Os textos que circulam nas esferas digitais apresentam leitura e produção bem diferenciadas do contexto real, uma vez que mesclam escritas, imagens, links, vídeos, etc., além de apresentar características próprias.

É essencial destacar a importância de a escola abordar as práticas de leitura e escrita também no meio digital. Afastar-se do que está sendo usado pelos discentes é criar barreiras para um aprendizado prazeroso.

Não podemos, como professores, deixar de trabalhar a habilidade de ler e escrever por meio de Memes e GIFS, podendo utilizar a intertextualidade, ou seja, ver um texto em outro, o humor, a criatividade, porque é possível fazer uso do verbal e não verbal, e o mais importante: desenvolver a criticidade no aluno.

Refletir sobre os gêneros que estão em circulação, nos diferentes espaços, é papel do professor de língua portuguesa. Assim, conhecer as habilidades pedagógicas a serem desenvolvidas com o uso de Memes e 
GIFS é poder exercer uma prática docente mais confiante e atual.

Diante da tarefa de formar leitores críticos e criar ambientes favoráveis para o aprender, usar os Memes e os GIFS, em sala de aula, é poder mostrar um ensino e aprendizado mais lúdico, uma vez que esses gêneros são fáceis de ler e elaborar, apresentando, regra geral, muito texto imagético. Simultaneamente, por serem esses gêneros bastante usados pelo público jovem, pensamos estar neles a possibilidade de criação, na escola, de leitores e produtores de textos críticos.

\section{REFERÊNCIAS}

BAZERMAN, C. Gêneros Textuais, Tipificação e Interação. São Paulo: Cortez, 2011.

BELLONI, M. L. Educação a Distância. Campinas, SP: Autores Associados, 1999.

BRASIL. Ministério da Educação e do Desporto. Parâmetros Curriculares Nacionais - $3^{\circ}$ e $4^{\circ}$ Ciclos. Língua Portuguesa. Brasília: MEC, 1998

ESCALANTE, P. O potencial comunicativo dos memes: formas de letramento na rede digital.120 folhas. Dissertação - UERJ. Rio de Janeiro, 2016.

FONTANELLA, F. O que vem de baixo nos atinge: intertextualidade, reconhecimento e prazer na cultura digital trash. Trabalho apresentado no IX Encontro dos Grupos/Núcleos de Pesquisas em Comunicação, evento componente do XXXII Congresso Brasileiro de Ciências da Comunicação, Curitiba, 2009a.

FONTANELLA, F. O que é um meme na Internet? Proposta para uma problemática da memesfera. Trabalho apresentado no III Simpósio Nacional da ABCiber, São Paulo, $2009 b$.

FIORIN, J. L. Introdução ao pensamento de Bakhtin. São Paulo: Ática, 2008.

LAIS, C. O USO DOS GÊNEROS DIGITAIS NA SALA DE AULA. Anais | I Simpósio Regional de Educação/Comunicação. Disponível em: http://geces.com.br/simposio/ anais/wp-content/uploads/2014/04/GENEROS_DIGITAIS.pdf. Acesso em: 29 mar. 2018.

LUPINACCI, L. As Apropriações GIF Animado: aspectos culturais, expressivos e afetivos dos usos de uma tecnologia defasada. 279 folhas. Dissertação - UFRGS. Rio Grande do Sul, 2016. Acessado em 22/01/2017. Disponível em $<<$ http://www.lume.ufrgs.br/ handle/10183/142516 >>

MARCUSCHI, L. A. Gêneros textuais: configuração, dinamicidade e circulação. In: KARWOSKI, A. M.; GAYDECZKA, B.; BRITO, K. S. (Orgs.). Gêneros textuais: reflexões e ensino. 3. ed. Rio de Janeiro: Nova Fronteira, 2008. p. 15- 26.

MARCUSCHI, L. A. Produção textual, análise de gêneros e compreensão. São Paulo: Parábola Editorial, 2008. p. 147-207. 
MARCUSCHI, L. A. Gêneros textuais emergentes no contexto da tecnologia digital. IN: MARCUSCHI, L. A.; XAVIER, A. C. (Orgs.). Hipertexto e gêneros digitais. São Paulo: Cortez, 2010a, p. 15-80.

MARCUSCHI, L. A. Gêneros textuais: definição e funcionalidade. IN: DIONISIO, A. P.; MACHADO, A. R.; BEZERRA, M. A. (Orgs.) Gêneros Textuais \& Ensino. São Paulo: Parábola Editorial, 2010b, p. 19-38.

MASSARUTO, F. A.; DO VALE, L. F.; ALAIMO, M. M. Educomunicação: O Meme Enquanto Gênero Textual A Ser Utilizado Na Sala De Aula. Revista Pandora Brasil - No 83 - Junho 2017 ISSN 2175-3318 - "Letras em Foco". http://revistapandorabrasil.com/ revista_pandora/letras_83/fillippo_lara_marcela.pdf. Acesso em: 20 jun. 2018.

RAMOS, M. R. V. O uso de tecnologias em sala de aula. Edição n. 2, Vol. 1, jul-dez. 2012. Disponível em: www.uel.br/...MARCIO\%20RAMOS\%20\%20ORIENT\%20PROF\%20 ANGELA.pdf. Acesso em: 28 mar. 2018.

REGIS; F. AUDI; G.; MAIA, A. Do Letramento ao Letramento Midiático: Práticas e Competências Cognitivas na Cibercultura. CONGRESSO BRASILEIRO DE CIÊNCIAS DA COMUNICAÇÃO, 37., 2014, Foz do Iguaçu. [Anais...]. Foz do Iguaçu, 2014.

ROJO, R. H. Gêneros Discursivos do Círculo de Bakhtin e multiletramentos. In. ROJO, R. H. (Org.). Escol@ Conectada - os multiletramentos e as TICs. São Paulo: Parábola Editorial, 2013, p. 13-36.

SOARES, M. Novas práticas de leitura e escrita: letramento digital. Educação e Sociedade, Campinas, v. 23, n. 81, p. 143-160, dez. 2002. Disponível em: http://www.scielo.br/pdf/ es/v23n81/13935.pdf - Acesso em: 25 jan. 2019.

SCHENEUWLY, B.; DOLZ, J. Os gêneros escolares - das práticas de linguagem aos objetos de ensino. IN: SCHENEUWLY, B.; DOLZ, J. e colaboradores. Gêneros Orais e Escritos na Escola. Campinas, SP: Mercado de Letras, 2004. 71-91.

XAVIER, A. C. Gêneros textuais emergentes no contexto da tecnologia digital. In: XAVIER, A. C. Hipertexto e gêneros digitais. Rio de Janeiro: Lucerna, 2005, p.13-67.

Recebido em: 03/05/2019

Aceite em: 10/02/2020 